\title{
Long-term outcomes following 90Y Radioembolization of neuroendocrine liver metastases: evaluation of the radiation-emitting SIR-spheres in non-resectable liver tumor (RESiN) registry
}

Thomas Y. Wong ${ }^{1}$, Kevin S. Zhang ${ }^{2}$, Ripal T. Gandhi ${ }^{3}$, Zachary S. Collins ${ }^{4}$, Ryan O'Hara ${ }^{5}$, Eric A. Wang ${ }^{6}$, Kirubahara Vaheesan ${ }^{7}$, Lea Matsuoka ${ }^{8}$, Daniel Y. Sze ${ }^{9}$, Andrew S. Kennedy ${ }^{10}$ and Daniel B. Brown ${ }^{1 *}$

\begin{abstract}
Background: The goal of this study was to evaluate efficacy and safety of $90 \mathrm{Y}$ radioembolization for neuroendocrine liver metastases (NELM) in a multicenter registry.

Methods: One hundred-seventy patients with NELM were enrolled in the registry (NCT 02685631). Prior treatments included hepatic resection $(n=23,14 \%)$, arterial therapy $(n=62,36 \%)$, octreotide $(n=119,83 \%)$, cytotoxic chemotherapy $(n=58,41 \%)$, biologic therapy $(n=49,33 \%)$ and immunotherapy $(n=10,6 \%)$. Seventy-seven (45\%) patients had extrahepatic disease. Seventy-eight (48\%), 61 (37\%), and 25 (15\%) patients were Eastern Cooperative Oncology Group (ECOG) performance status of 0, 1, or $\geq 2$. Tumor grade was known in 81 (48\%) patients: 57 (70\%) were well-, 12 (15\%) moderate-, and 12 (15\%) poorly-differentiated. Kaplan-Meier analysis and log rank tests were performed to compare overall and progression-free survival (OS/PFS) by tumor location and grade. Toxicities were reported using Common Terminology Criteria for Adverse Events v.5. Cox Proportional Hazards were calculated for pancreatic primary, performance status, extrahepatic disease at treatment, unilobar treatment, baseline ascites, and $>25 \%$ tumor burden.

Results: One, 2, and 3-year OS rates were 75, 62 and 46\%, respectively. Median OS was 33 months [(95\% Cl: 25-not reached (NR)]. The longest median OS was in patients with pancreatic (42 months, 95\% Cl: 33-NR) and hindgut 41 months, 95\% Cl: 12-NR) primaries. The shortest OS was in foregut primaries (26 months; $95 \%$ Cl: $23-N R ; X^{2}=7$, $p=0.1$ ). Median OS of well-differentiated tumors was 36 months ( $95 \% \mathrm{Cl}: 10-\mathrm{NR}$ ), compared to 44 (95\% Cl: 7-NR) and 25 (95\% Cl: 3-NR) months for moderate and poorly differentiated tumors. Median progression-free survival (PFS) was 25 months with 1,2, and 3-year PFS rates of 70,54, and 35\%, respectively. Thirteen patients (7.6\%) developed grade 3 hepatic toxicity, most commonly new ascites $(n=8,5 \%)$ at a median of 5.5 months. Performance status of $\geq 2$ (HR 2.7, $p=0.01)$ and baseline ascites (HR 2.8, $P=0.049)$ predicted shorter OS.
\end{abstract}

\footnotetext{
*Correspondence: daniel.b.brown@vumc.org

1 Department of Radiology and Radiological Sciences, Vanderbilt

University Medical Center, 1161 21st Avenue S, CCC-1118 Medical Center

North, Nashville, TN 37232, USA

Full list of author information is available at the end of the article
}

(C) The Author(s) 2022. Open Access This article is licensed under a Creative Commons Attribution 4.0 International License, which permits use, sharing, adaptation, distribution and reproduction in any medium or format, as long as you give appropriate credit to the original author(s) and the source, provide a link to the Creative Commons licence, and indicate if changes were made. The images or other third party material in this article are included in the article's Creative Commons licence, unless indicated otherwise in a credit line to the material. If material is not included in the article's Creative Commons licence and your intended use is not permitted by statutory regulation or exceeds the permitted use, you will need to obtain permission directly from the copyright holder. To view a copy of this licence, visit http://creativecommons.org/licenses/by/4.0/. The Creative Commons Public Domain Dedication waiver (http://creativeco mmons.org/publicdomain/zero/1.0/) applies to the data made available in this article, unless otherwise stated in a credit line to the data. 
Discussion: In a population with a high incidence of extrahepatic disease, $90 \mathrm{Y}$ was effective and safe in treatment of NELM, with median OS of 41 months for well differentiated tumors. Grade 3 or greater hepatic toxicity was developed in $7.6 \%$ of patients.

Trial registration: NCT 02685631.

Keywords: Neuroendocrine tumor, Metastases, Liver cancer

\section{Introduction}

The incidence of neuroendocrine tumors (NET) is increasing from an annual incidence of 1.1/100,000 people in 1973 to 7.0 per 100,000 in 2012 [1]. Approximately one-quarter of neuroendocrine patients have metastatic disease at presentation and $80 \%$ eventually develop liver metastases [1, 2]. Development of hepatic metastases is associated with shorter 5- and 10-year overall survival (OS) [3]. Many patients are initially treated with somatostatin analogs, agents which limit hormone production and are also cytostatic [4-7]. Patients with paraneoplastic symptoms or progressive disease breaking through somatostatin analogs require additional therapy [7]. Recommendations for patients with progressive lowor intermediate-grade liver-dominant disease include everolimus, peptide-receptor radiation therapy (PRRT), and arterial therapy including bland embolization, chemoembolization, and radioembolization.

Selection of the therapeutic arterial modality for neuroendocrine liver metastases (NELM) varies widely without standardization. Multiple studies failed to identify a superior OS across different arterial techniques [8-11]. One retrospective study described longer OS with chemoembolization compared to TARE [12]. Similarly, periprocedural toxicity profiles from TARE were similar to other arterial therapies in several studies $[3,9,10,13,14]$. NET patients have projected OS of 27-35 months following TARE despite presenting with bilobar hepatic metastases [9, 14-16]. Recent literature described chronic imaging changes of portal hypertension in NET patients who had prolonged survival following radioembolization $[17,18]$. Additionally, a recent report described a $13 \%$ incidence of chronic hepatic toxicity following TARE in NET patients [19]. All the studies above had 64 or fewer patients undergoing TARE. Given the expected multiyear survival, particularly with lowgrade NELM, further definition of survival and toxicity from TARE to treat NELM would be helpful. Given the increasing utilization of PRRT, toxicity in patients who undergo both PRRT and TARE is an area of interest [20].

The Radiation-Emitting SIR-Spheres in Non-Resectable liver tumor (RESiN) registry (NCT 02685631) is a multicenter, prospective observational data collection tracking demographics, dosimetry, treatment response, and therapy toxicity of resin embedded Yttrium-90 microspheres
(Sir-Spheres; Sirtex Medical, Woburn Massachusetts) in different tumor types. The purpose of the current manuscript is to further characterize efficacy and toxicity of TARE in patients with NELM.

\section{Materials and methods}

A total of 170 patients (74 women/96 men) with NELM were enrolled in RESiN across 36 institutions between 2015 and 2020. Institutional review board approval was obtained at each site and all patients signed informed consent. Patients received TARE in interventional radiology at the participating centers as part of multidisciplinary decision making for their care. Inclusion criteria for RESiN included appropriateness for arterial therapy in a patient $\geq 18$ years of age and ability of the patient to provide informed consent. Data was entered into a Research Electronic Data CAPture (REDCap) database. As RESiN is an observational registry, patients were treated and followed using local institutional guidelines. No incentives for compliance were provided to enrollees.

Table 1 outlines demographic information within the registry. The majority of patients were male $(n=96,56 \%)$ and white $(n=140,82 \%)$. Eastern Cooperative Oncology Group (ECOG) performance status scores were 1 or greater in greater than half the patients $(n=86,51 \%)$. Of the 81 ( $48 \%$ of the registry) patients with available tumor grade using mitotic index: 57 (70\%) were well-, 12 (15\%) were moderate-, and 12 (15\%) were poorly-differentiated. The most common primary site was midgut $(n=54,36 \%)$ followed by foregut $(n=39,26 \%)$, pancreatic $(n=36$, $24 \%)$, and hindgut $(n=10,7 \%)$. Thirteen patients $(9 \%)$ had an unknown primary site. Fifteen patients (9\% of the registry) had prior biliary interventions with Whipple procedure as the most common $(n=5,31 \%)$. Each site followed its own protocol to prevent cholangitis or abscess from colonized bile ducts.

Median hepatic tumor burden at treatment was 26\% (IQR: 11.8-49.7\%). Seventy-seven patients (45\%) had extrahepatic metastatic disease and ten patients (6\%) had ascites. Before TARE, 23 patients underwent hepatic resection and 62 received arterial therapy. One hundred forty-four patients (85\%) received cytostatic or systemic therapy. The most commonly prescribed agent was one of the octreotide analogs $(n=119 / 144,83 \%)$. Fifty-eight patients $(40 \%)$ underwent cytotoxic chemotherapy, 49 
Table 1 Baseline demographics of the treatment group

\begin{tabular}{|c|c|c|}
\hline \multirow{2}{*}{ Gender $(n=170)$} & Female & $74(44 \%)$ \\
\hline & Male & $96(56 \%)$ \\
\hline \multicolumn{2}{|l|}{ Age (Median [IQR]) } & $65.5[56.0-73.0]$ \\
\hline \multirow[t]{7}{*}{ Race $(n=170)$} & American Indian or Alaska Native & $0(0 \%)$ \\
\hline & Asian & $3(2 \%)$ \\
\hline & Black or African American & $16(9 \%)$ \\
\hline & Native Hawaiian or Pacific Islander & $1(1 \%)$ \\
\hline & White or Caucasian & $140(82 \%)$ \\
\hline & Unknown & $7(4 \%)$ \\
\hline & Other & $3(2 \%)$ \\
\hline \multirow[t]{4}{*}{ Ethnicity $(n=170)$} & Hispanic or Latino & $19(11 \%)$ \\
\hline & Non-Hispanic & $137(81 \%)$ \\
\hline & Unknown & $14(8 \%)$ \\
\hline & Other & $0(0 \%)$ \\
\hline \multirow[t]{6}{*}{ Enrollment Year $(n=170)$} & 2015 & $7(4 \%)$ \\
\hline & 2016 & $37(22 \%)$ \\
\hline & 2017 & $68(40 \%)$ \\
\hline & 2018 & $26(15 \%)$ \\
\hline & 2019 & $23(14 \%)$ \\
\hline & 2020 & $9(5 \%)$ \\
\hline \multirow[t]{3}{*}{$\operatorname{ECOG}(n=164)$} & 0 & $78(48 \%)$ \\
\hline & 1 & $61(37 \%)$ \\
\hline & 2 or more & $25(15 \%)$ \\
\hline \multirow[t]{3}{*}{ Grade $(n=81)$} & Well Differentiated & $57(70 \%)$ \\
\hline & Moderately Differentiated & $12(15 \%)$ \\
\hline & Poorly Differentiated & $12(15 \%)$ \\
\hline \multirow[t]{5}{*}{ Tumor Site $(n=152)$} & Foregut & $39(26 \%)$ \\
\hline & Midgut & $54(36 \%)$ \\
\hline & Pancreas & $36(24 \%)$ \\
\hline & Hindgut & $10(7 \%)$ \\
\hline & Unknown & $13(9 \%)$ \\
\hline \multicolumn{2}{|l|}{ Tumor Burden \% (Median [IQR]) } & 25.9 [11.9-49.8] \\
\hline \multirow[t]{2}{*}{ Tumor Location $(n=165)$} & Bilobar & $77(47 \%)$ \\
\hline & Unilobar & $88(53 \%)$ \\
\hline \multicolumn{3}{|l|}{ Extrahepatic Metastasis $(n=161)$} \\
\hline \multirow[t]{11}{*}{ Yes $(n=77,48 \%)$} & Lung & $22(29 \%)$ \\
\hline & Lymph Nodes & $22(29 \%)$ \\
\hline & Bone & $14(18 \%)$ \\
\hline & Peritoneum & $9(12 \%)$ \\
\hline & Small Bowel & $6(8 \%)$ \\
\hline & Brain & $1(1 \%)$ \\
\hline & Gastric & $1(1 \%)$ \\
\hline & Large Bowel & $1(1 \%)$ \\
\hline & Prostate & $1(1 \%)$ \\
\hline & Uterus & $1(1 \%)$ \\
\hline & Other & $28(36 \%)$ \\
\hline \multicolumn{3}{|l|}{ No $(n=85,52 \%)$} \\
\hline Hepatic Resection & Yes & $23(14 \%)$ \\
\hline
\end{tabular}


Table 1 (continued)

\begin{tabular}{|c|c|c|}
\hline \multirow[t]{3}{*}{ Systemic Therapy $(n=144)$} & Octreotide & $119(83 \%)$ \\
\hline & Biologic & $49(34 \%)$ \\
\hline & Cytotoxic & $58(40 \%)$ \\
\hline \multirow[t]{2}{*}{ Arterial Embolization $(n=166)$} & Yes & $62(37 \%)$ \\
\hline & No & $104(63 \%)$ \\
\hline \multirow[t]{5}{*}{ Biliary Intervention $(n=15)$} & Metallic Stent & $2(13 \%)$ \\
\hline & Plastic Stent & $1(7 \%)$ \\
\hline & Percutaneous Biliary Drainage & $1(7 \%)$ \\
\hline & Surgical Anastomosis & $5(31 \%)$ \\
\hline & Other & $7(47 \%)$ \\
\hline Ascites & & $10(6 \%)$ \\
\hline \multirow[t]{8}{*}{ Baseline Laboratories } & Bilirubin in mg/dL (Median [IQR]) & $0.9[0.6-1.4]$ \\
\hline & Albumin in g/dL (Median [IQR]) & $4.1[3.8-4.3]$ \\
\hline & ALT in u/L (Median [IQR]) & $42.0[23.8-73.0]$ \\
\hline & AST in u/L (Median [IQR]) & $52.0[28.0-72.0]$ \\
\hline & INR Ratio (Median [IQR]) & $1.1[1.0-1.3]$ \\
\hline & Creatinine in mg/dL (Median [IQR]) & $1.1[0.9-1.4]$ \\
\hline & Chromogranin A in ng/mL (Median [IQR]) & $543[215-2981]$ \\
\hline & Platelet Count in thousands/uL (Median [IQR]) & $239.5[170.5-315.8]$ \\
\hline
\end{tabular}

IQR interquartile range

Table 2 Previous treatments received by patients in the study

\begin{tabular}{ll}
\hline Agent Type & $\begin{array}{c}\text { Number } \\
\text { Treated }\end{array}$ \\
\hline Alkylating Agent & 20 \\
$\quad$ Temozolomide & 8 \\
$\quad$ Cisplatin & 6 \\
$\quad$ Oxaliplatin & \\
Topoisomerase Inhibitor & 9 \\
$\quad$ Irinotecan & \\
Antimetabolite & 24 \\
$\quad$ Capecitabine & \\
DNA Synthesis Inhibitor & 12 \\
$\quad$ Etoposide & \\
m-TOR Inhibitor & \\
Everolimus & 42 \\
Sirolimus & 1 \\
VEGF Inhibitor & \\
Sunitinib & 6 \\
PD-1 Inhibitor & \\
Pembrolizumab & Nivolumab \\
CTLA-4 Blockade & \\
Ipilimumab & 4 \\
\hline
\end{tabular}

Table 3 Treatment history of patients undergoing more than one cycle of radioembolization

\begin{tabular}{lll}
\hline Patient Number & Area Treated & Treatment Date \\
\hline 1 & Bilobar & $1 / 24 / 2017$ \\
& Left Lobe & $2 / 22 / 2017$ \\
& Bilobar & $4 / 20 / 2018$ \\
& Right Lobe & $8 / 7 / 2018$ \\
2 & Bilobar & $3 / 18 / 2018$ \\
& Left Lobe & $2 / 20 / 2020$ \\
3 & Right Lobe & $4 / 3 / 2020$ \\
& Right Lobe & $8 / 3 / 2016$ \\
& Bilobar & $8 / 6 / 2019$ \\
4 & Bilobar & $9 / 3 / 2019$ \\
& Bilobar & $1 / 3 / 2019$ \\
& Bilobar & $2 / 11 / 2019$ \\
& Right Lobe & $4 / 23 / 2019$ \\
\hline
\end{tabular}

(34\%) received targeted therapy, and 10 (6\%) received immunotherapy as outlined in Table 2.

Dosimetry methods were available in 94 patients (55\%). Body surface area (BSA) was the most commonly utilized method ( $n=86,91 \%)$. One hundred and sixty-six patients (98\%) underwent a single cycle of therapy, while four patients received more than one cycle of treatment as described in Table 3.

In total, 82 patients (48\%) underwent bilobar and 88 (52\%) had unilobar treatment. Median prescribed activity 

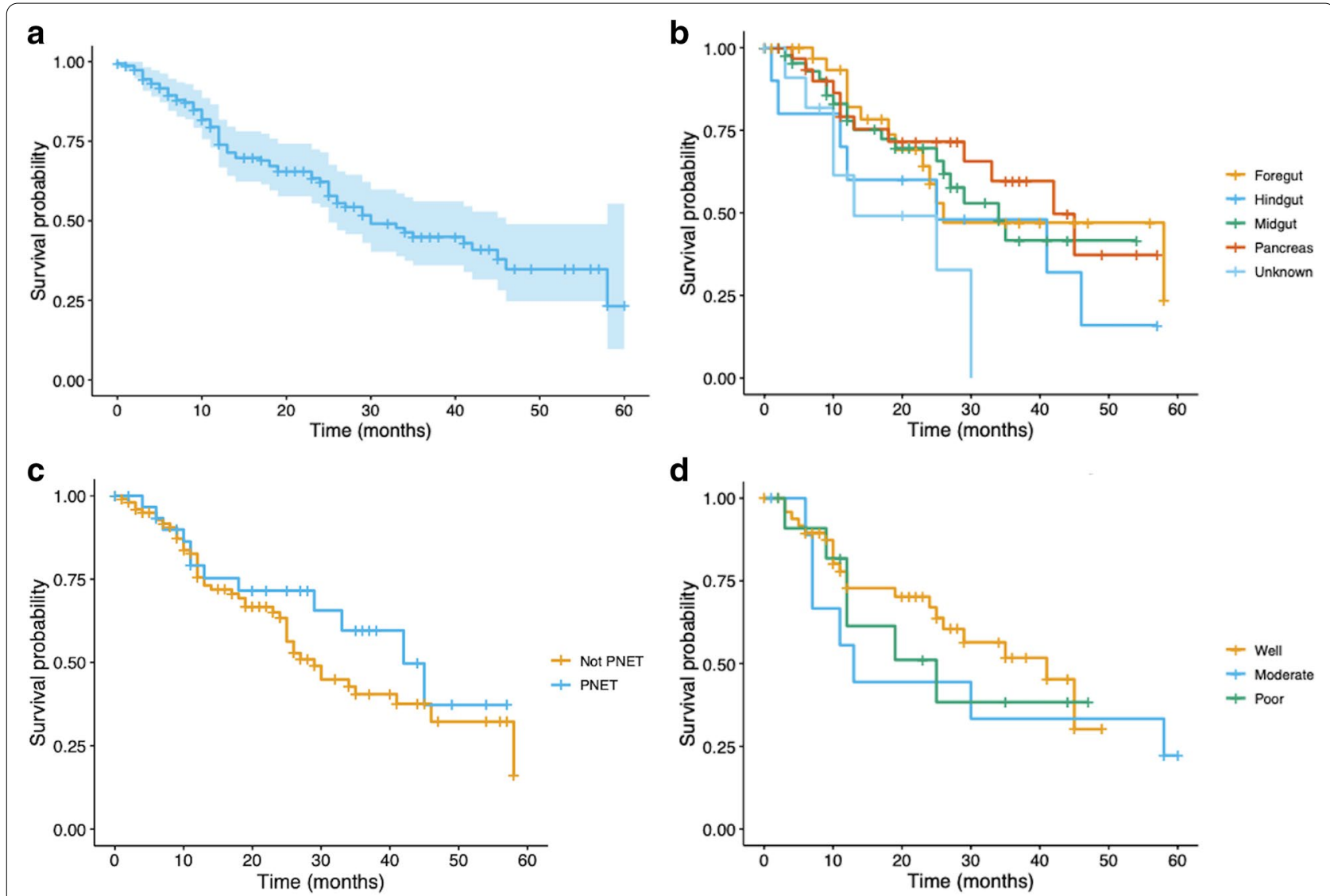

Fig. 1 A-D Overall survival (A) for the entire cohort (B) by primary NET location (C) for Pancreatic primary (PNET) compared to all other primary tumors and $(\mathbf{D})$ by tumor grade

was $1.3 \mathrm{GBq}$ (IQR: $0.9-1.5 \mathrm{GBq})$ and $1.9 \mathrm{GBq}(\mathrm{IQR}: 1.7-$ $2.2 \mathrm{GBq}$ ) for uni- and bilobar treatments, respectively. Use of peptide receptor radiotherapy (PRRT) before or after TARE was tracked.

Follow-up imaging and lab studies were obtained per operator and institutional protocols. Tumor response including progression was assessed utilizing Response Evaluation Criteria in Solid Tumors (RECIST 1.1) at 6 months after treatment given the reported median time to response of 4.9 months [21]. Objective response rate (ORR) was the sum of complete and partial responses. Disease control rate (DCR) was ORR plus stable disease. Patients were censored at the time of last contact and follow-up continued through August, 2021.

Kaplan-Meier analysis and log rank tests were performed to compare OS and PFS for the entire cohort as well as by tumor grade and location. Based on trends towards lower survival with pancreatic primaries in a meta-analysis, OS and PFS were also calculated for pancreatic primaries versus the remaining group [16]. PFS end points included: progressive disease at imaging, death without progression, or transition to hospice.
Toxicities were reported using Common Terminology Criteria for Adverse Events v.5. Any patients receiving PRRT were tracked for hepatic function toxicity. Additionally, the cohort was divided into two groups: enrollment prior to (2015-2017) and following (2018-2020) the publication of the NETTER-1 trial [22] to estimate changes in enrollment rate using an exact binomial test.

Cox proportional hazards regression was performed for the following factors at treatment: pancreatic primary tumor, ECOG score of 1 or $\geq 2$, unilobar treatment, extrahepatic disease, ascites, and tumor burden of $\geq 25 \%$. All values were significant at a $p<0.05$. All statistics were calculated using R Foundation for Statistical Computing,version 4.1.1 (Vienna, Austria).

\section{Results}

\section{Survival}

Median OS for the entire cohort was 33 months [(95\% CI: 25-not reached (NR)]. with 1-, 2-, and 3-year OS rates of 75,62 , and $46 \%$ (Fig. 1a). The differences in OS by primary tumor location were not statistically significant (Fig. $1 \mathrm{~b}, \mathrm{X}^{2}=7.0, p=0.1$ ). The longest $\mathrm{OS}$ was in patients 

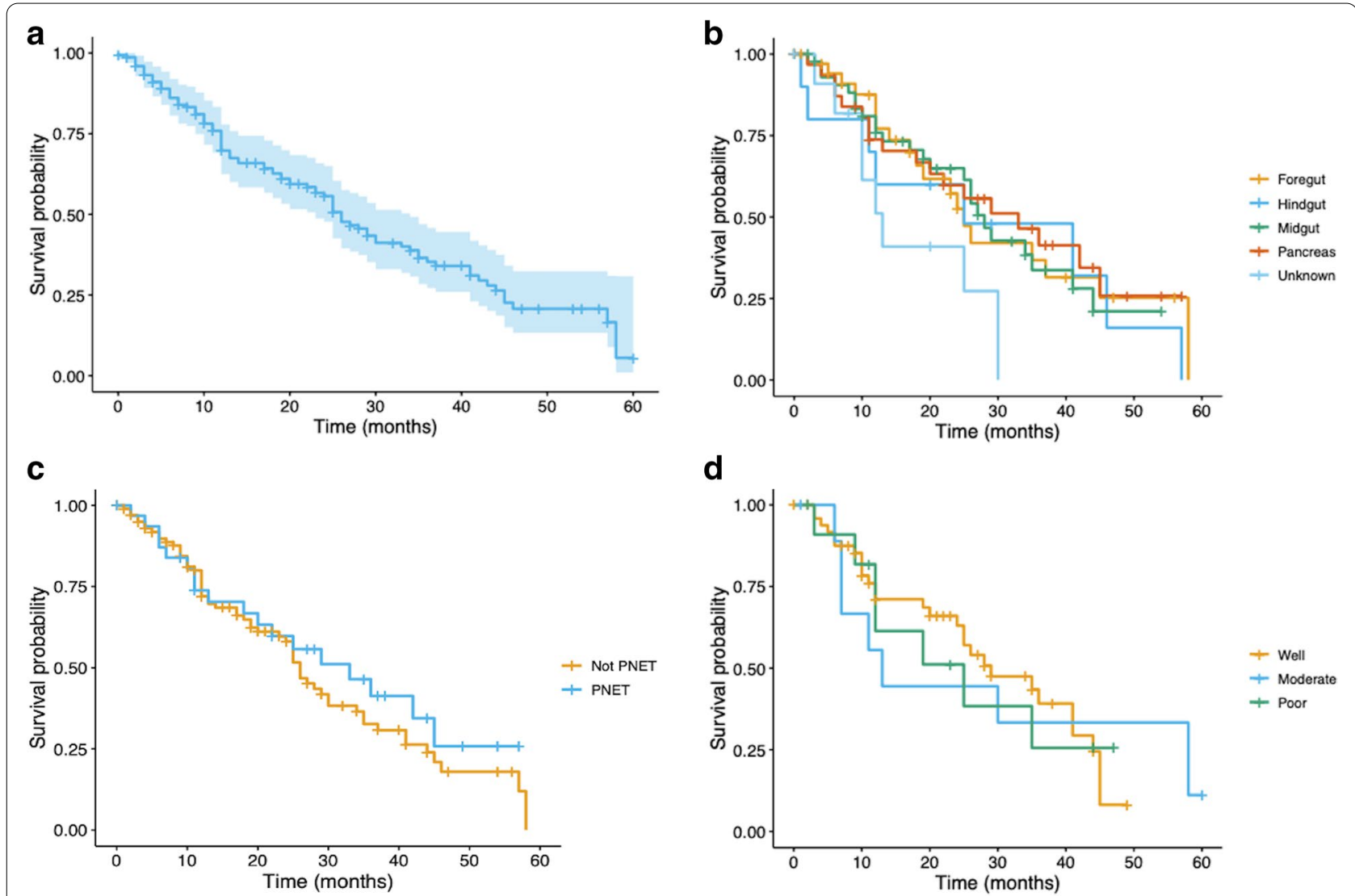

Fig. 2 A-D Progression-Free Survival (A) for the entire cohort (B) by primary location (C) for pancreatic primary tumors (PNET) vs all other types combined and (D) by tumor grade

with pancreas (42 months; 95\% CI: 33-NR) and hindgut tumors (41 months; $95 \%$ CI: 12-NR). OS was relatively shorter in midgut (35 months; 95\% CI: $25-\mathrm{NR}$ ), foregut (26 months; 95\% CI: 23-NR) and unknown primary locations (25 months; $95 \%$ CI: 10-NR). Pancreatic primary tumor OS (42 months; $95 \%$ CI: 33-NR) was longer than all other groups combined ( 29 months, 95\% CI: 25-NR) although this outcome was not statistically significant $(p=0.3) \quad$ (Fig. 1c). Well-differentiated tumors had a median OS of 41 months (95\% CI: 26-NR), compared to 13 (95\% CI: 7-NR) and 25 months (95\% CI: 12-NR) for moderate- and poorly-differentiated tumors, respectively (Fig. 1d). This difference was not statistically significant $(p=0.67)$.

PFS for the entire group was 25 months (95\% CI: 22-35 months) with 1-, 2-, and 3-year PFS rates of 70, 54, and $35 \%$ (Fig. 2a). There was no significant difference for PFS among primary locations (Fig. $2 \mathrm{~b}, \mathrm{X}^{2}=4.8, p=0.3$ ). PFS was 2 years or greater for pancreatic (33 months, 95\% CI: 18-NR), midgut (29months, 95\% CI: 20-NR), hindgut (25 months, $95 \%$ CI: $12-\mathrm{NR}$ ), and foregut (24 months, 95\% CI: 18-NR) primaries, while 13 months (95\% CI:
10-NR) for unknown primary location. Median PFS for pancreatic primary tumors (33 months, 95\% CI: 20-NR) was longer than for all other tumor groups combined (26 months, 95\% CI: 24-34; $p=0.4$ ) (Fig. 2c). PFS was longest in well-differentiated tumors at a median of 35 months (95\% CI: 25-NR), compared with 13 (95\% CI: 7-NR) and 25 (95\% CI: 12-NR) months in moderate- and poorly-differentiated tumors, respectively (Fig. 2d). This difference was not statistically significant $(p=0.96)$.

\section{Imaging response, progression and death}

Post-treatment imaging was performed at 6 months on 121 patients. Ninety-nine patients had RECIST scoring performed. In this group, five $(4 \%)$ had complete response, 39 (32\%) had a partial response, $39(32 \%)$ had stable disease and $16(13 \%)$ had progressive disease. Forty-four patients (36\%) had an objective response and 83 patients (69\%) had disease control at 6 months. Seventy-one patients (42\%) developed intrahepatic progressive disease. Twenty-six patients (37\% of the cohort) developed progressive disease within a previously treated region while the remaining 45 patients (63\%) with 
intrahepatic progression developed in an untreated area of liver. Sixty-one patients (36\%) developed new extrahepatic disease. The most common site of new extrahepatic disease was skeletal $(n=23,38 \%)$.

Sixty-seven patients (39\% of the cohort) died, with data regarding cause of death available in 44 (66\% of expired patients). Tumor progression was the most commonly described cause of death $(n=33,49 \%$ of expired patients). One patient ( $2 \%$ of expired patients, $0.6 \%$ of the entire cohort) died of liver failure 11 months after treatment. Prior to TARE, this patient had received multiple types of chemotherapy including cisplatin and irinotecan. The remaining patients died of other causes. An additional 10 patients (6\%) were lost to follow-up, and 6 (4\%) signed into hospice. One patient left the study to seek treatment at a different institution and another left the study for unknown reasons.

\section{Cox proportional-Hazard model}

The Cox Models for OS and PFS are in Table 5. Hazard ratios for OS were significant in patients with an ECOG score of 2 or greater (HR: 2.7, $p=0.01$ ) and in the setting of baseline ascites (HR: 2.8, $p=0.049$ ).

Similarly, hazard ratios for PFS were greater with an ECOG score of 2 or greater (HR: 2.4, $p=0.01$ ) and baseline ascites (HR: 4.9, $p=0.0001$ ). Patients with unilobar treatment (HR: 0.6, $p=0.03$ ) and those with $25 \%$ or greater tumor burden (HR: 0.6, $p=0.049$ ) also had a longer progression-free survival.

\section{Toxicities}

Grade 3 or greater toxicities developed in 58 patients (34\%) and are outlined in Table 4. Constitutional significant adverse events with an incidence of $5(3 \%)$ or greater included: abdominal pain $(n=7,4 \%)$ and anorexia $(n=5$, $3 \%)$. Of the 15 patients with colonized bile ducts, one patient $(7 \%)$ developed a hepatic abscess. Nineteen toxicities $(20 \%)$ were attributed as definitely or probably related to treatment. These included all liver function toxicities in the absence of progressive hepatic disease including bilirubin $(\mathrm{n}=5,3 \%)$, new ascites $(n=8,5 \%)$, alanine aminotransferase $(n=1,0.6 \%)$ and alkaline phosphatase $(\mathrm{n}=1,0.6 \%)$. Of the 5 patients with Grade 3 hyperbilirubinemia, 2 normalized within 3 months, leaving 13 (7.6\%) with durable hepatic function toxicities. The other three cases developed at 2.6, 8.9, and 11.5 months after TARE. Development of new ascites was identified a median of 5.5 months after treatment (range 3.5-18 months). Additional events included the death noted above (grade 5), two cases of abdominal pain (grade 3 and 4), one hepatic abscess (grade 3 ), and a single grade 3 lymphopenia.
Table 4 Toxicities and attributions

\begin{tabular}{|c|c|c|c|c|}
\hline Adverse Events & Grade 3 & Grade 4 & Grade 5 & Total \\
\hline Abdominal Infection & 1 & 0 & 0 & 1 \\
\hline Abdominal Pain & 5 & 1 & 1 & 7 \\
\hline Acute Kidney Injury & 1 & 0 & 0 & 1 \\
\hline Alanine Aminotransferase & 1 & 0 & 0 & 1 \\
\hline Alkaline Phosphatase Increase & 1 & 0 & 0 & 1 \\
\hline Anemia & 2 & 0 & 0 & 2 \\
\hline Anorexia & 5 & 0 & 0 & 5 \\
\hline Ascites, New & 8 & 0 & 0 & 8 \\
\hline Bilirubin & 5 & 0 & 0 & 5 \\
\hline Aspiration & 1 & 0 & 0 & 1 \\
\hline Atrial Fibrillation & 1 & 0 & 1 & 2 \\
\hline Chronic Kidney Injury & 1 & 0 & 0 & 1 \\
\hline Death Not Otherwise Specified & 0 & 0 & 24 & 24 \\
\hline Dehydration & 3 & 0 & 0 & 3 \\
\hline Diarrhea & 2 & 0 & 0 & 2 \\
\hline Duodenal Hemorrhage & 1 & 0 & 0 & 1 \\
\hline Dyspnea & 1 & 0 & 0 & 1 \\
\hline Edema, Cerebral & 0 & 1 & 0 & 1 \\
\hline Edema, Limb & 0 & 1 & 0 & 1 \\
\hline Encephalopathy & 1 & 0 & 0 & 1 \\
\hline Fall & 1 & 0 & 0 & 1 \\
\hline Febrile Neutropenia & 2 & 0 & 0 & 2 \\
\hline Generalized Muscle Weakness & 4 & 0 & 0 & 4 \\
\hline Headache & 1 & 0 & 0 & 1 \\
\hline Hemorrhoids & 1 & 0 & 0 & 1 \\
\hline Hepatic Failure & 0 & 0 & 1 & 1 \\
\hline Hepatic Infection & 2 & 0 & 0 & 2 \\
\hline Hyperglycemia & 1 & 0 & 0 & 1 \\
\hline Hyperkalemia & 1 & 0 & 0 & 1 \\
\hline Hypernatremia & 1 & 0 & 0 & 1 \\
\hline Hypertension & 0 & 1 & 0 & 1 \\
\hline Hyperuricemia & 1 & 1 & 0 & 2 \\
\hline Hypokalemia & 2 & 2 & 0 & 4 \\
\hline Hypophosphatemia & 1 & 0 & 0 & 1 \\
\hline Hypoxia & 0 & 1 & 0 & 1 \\
\hline Hypoxia & 0 & 1 & 0 & 1 \\
\hline Ileus & 1 & 0 & 0 & 1 \\
\hline Leukocytosis & 1 & 0 & 0 & 1 \\
\hline Localized Edema & 1 & 0 & 0 & 1 \\
\hline Lymphopenia & 1 & 0 & 0 & 1 \\
\hline Nausea & 1 & 0 & 0 & 1 \\
\hline Other & 11 & 1 & 4 & 16 \\
\hline Pain & 1 & 0 & 0 & 1 \\
\hline Penile Infection & 1 & 0 & 0 & 1 \\
\hline Platelet Count Decreased & 1 & 2 & 0 & 3 \\
\hline Pleural Effusion & 1 & 0 & 0 & 1 \\
\hline Pneumonitis & 1 & 0 & 0 & 1 \\
\hline Seizure & 1 & 0 & 0 & 1 \\
\hline Sepsis & 2 & 1 & 0 & 3 \\
\hline
\end{tabular}


Table 4 (continued)

\begin{tabular}{lllll}
\hline Adverse Events & Grade & Grade & Grade & Total \\
\hline Small Intestinal Obstruction & 2 & 0 & 0 & 2 \\
Stroke & 1 & 0 & 0 & 1 \\
Surgical/Medical Procedures, & 1 & 0 & 0 & 1 \\
Other & & & & \\
Syncope & 0 & 1 & 0 & 1 \\
Tricuspid Valve Disease & 1 & 0 & 0 & 1 \\
Tumor Lysis Syndrome & 1 & 0 & 0 & 1 \\
Urinary Tract Infection & 3 & 0 & 0 & 3 \\
Vomiting & 3 & 0 & 0 & 3 \\
Total & $\mathbf{9 4}$ & $\mathbf{1 4}$ & $\mathbf{3 1}$ & $\mathbf{1 3 9}$ \\
Attribution & & & & \\
$\quad$ Definite & $\mathbf{1 2}$ & $\mathbf{0}$ & $\mathbf{1}$ & $\mathbf{1 3}$ \\
Probable & $\mathbf{5}$ & $\mathbf{2}$ & $\mathbf{0}$ & $\mathbf{7}$ \\
Possible & $\mathbf{0}$ & $\mathbf{0}$ & $\mathbf{0}$ & $\mathbf{0}$ \\
Unlikely & $\mathbf{1 2}$ & $\mathbf{3}$ & $\mathbf{3}$ & $\mathbf{1 8}$ \\
Unrelated & $\mathbf{3 7}$ & $\mathbf{6}$ & $\mathbf{2 6}$ & $\mathbf{6 9}$ \\
Unknown & $\mathbf{0}$ & $\mathbf{0}$ & $\mathbf{0}$ & $\mathbf{0}$ \\
Missing & $\mathbf{3 0}$ & $\mathbf{2}$ & $\mathbf{0}$ & $\mathbf{3 2}$ \\
\hline
\end{tabular}

Table 5 Cox Proportional Hazard for Overall and ProgressionFree Survival

\begin{tabular}{lllll}
\hline Value & Coefficient & $\mathbf{z}$ & Hazard Ratio & $P$-value \\
\hline Overall Survival & & & & \\
PNET vs Other & -0.2 & -0.5 & 0.8 & 0.6 \\
ECOG 1 vs 0 & 0.1 & 0.5 & 1.2 & 0.7 \\
ECOG 2 vs 0 & 0.9 & 2.5 & 2.7 & 0.01 \\
Extrahepatic Disease & 0.3 & 0.9 & 1.3 & 0.4 \\
Unilobar Treatment & -0.5 & -1.9 & 0.6 & 0.06 \\
Ascites & 1.0 & 2.0 & 2.8 & 0.049 \\
$\geq$ 25\% Tumor Burden & -0.3 & -1.1 & 0.7 & 0.3 \\
Progression-Free Survival & & & \\
PNET vs Other & -0.2 & -0.5 & 0.9 & 0.6 \\
ECOG 1 vs 0 & -0.09 & -0.3 & 0.9 & 0.7 \\
ECOG 2 vs 0 & 0.9 & 2.5 & 2.4 & 0.01 \\
Extrahepatic Disease & 0.4 & 1.4 & 1.4 & 0.2 \\
Unilobar Treatment & -0.5 & -2.1 & 0.6 & 0.03 \\
Ascites & 1.6 & 3.8 & 4.9 & 0.0001 \\
$\geq 25 \%$ Tumor Burden & -0.5 & -2.0 & 0.6 & 0.049 \\
\hline
\end{tabular}

\section{PRRT}

Nine patients (5\%) underwent PRRT. All patients received PRRT after TARE at a median of 21 months after radioembolization (range 12-37 months). In five patients, the indication was extrahepatic progression, while two patients had intra- and extrahepatic progression. Two patients did not have information regarding the indication for PRRT. Two patients developed grade 3 bilirubin toxicities in the setting of progression of hepatic disease 18 and 24 months after PRRT; both patients were 42 months from TARE. No other grade 3 toxicities developed. NET patient enrollment decreased following FDA approval of PRRT in January 2018. From 2015 to 2017, 112 patients were enrolled. From 2018 to 2020, 58 patients were enrolled. This difference was statistically significant $(p<0.001)$.

\section{Discussion/conclusion} Discussion

The development of hepatic metastases is a major determinant of OS in patients with metastatic neuroendocrine tumor. The 5-year overall survival of hindgut NET drops from 75 to 88 to $30 \%$ and the OS of gastrinoma drops from $95 \%$ at 20 years to $15 \%$ at 10 years with development of liver metastases [3]. In the current study, we report a median OS of 33 months following resin TARE for NET. Three-year OS was $46 \%$. This group was not treatment naive: $14 \%$ of the patients had undergone hepatic resection, 36\% had previous arterial interventions, while 34 and $41 \%$ had received biologic or cytotoxic chemotherapy. As a result, 36\% of the patients were ECOG 1 and $15 \%$ were ECOG 2 or greater. Additionally, $45 \%$ of the cohort had both bilobar tumor as well as extrahepatic metastases. Patients with ECOG 2 or greater performance status or ascites at time of treatment had shorter OS and PFS. Unilobar therapy and greater than 25\% hepatic involvement was associated with longer PFS. In many malignancies, a greater disease burden would predict a shorter PFS. However, with the slow growth rate of many NET, it is possible that the longer PFS with greater than $25 \%$ burden was due to the greater tumor volume needed to reach progressive disease. Extrahepatic disease and a pancreatic primary had no statistically significant effect on OS or PFS.

OS in the current study resembles that of the multicenter CIRSE Registry for SIR-Spheres Therapy (CIRT) [15]. OS for the 58 NET patients in that study was 33 months as well. CIRT featured a higher percentage of ECOG 0 patients $(65.5 \%$ vs $47 \%$ in the current study). However, CIRT had more patients with bilobar disease $(87.8 \%$ vs $45 \%)$. Tumor burden was relatively similar between CIRT and the current study (median 20.8\% vs $25.7 \%)$. OS in the current study is also similar to the 34.4 months reported in 40 patients treated with glass microspheres [21]. Three-year OS in the current study and Memon et al. is also similar: $46 \%$ compared with $45 \%$ by Memon et al. The ORR and DCR in the current study (44 and $83 \%$, respectively) are also similar to 50 and $86 \%$ reported in a TARE metanalysis by Devcic et al. [16]

Subgroup analysis of NET primary locations is inconsistently described in publications using arterial therapy. 
The current study did not identify a difference in OS or PFS between primary locations. Patients with pancreatic NET are commonly diagnosed at a higher stage than other primaries [23]. This factor likely contributes to the lower OS of this subgroup compared to other subtypes. Many studies group non-pancreatic tumors together as a result. A survival advantage for non-pancreatic NET has been reported following embolization and chemoembolization [24-28]. Gupta et al. reported radiographic response in only $35.2 \%$ of pancreatic primaries, compared with $66.7 \%$ of carcinoid tumors from other sites [24]. This discrepancy has not been identified with TARE $[29,30]$. Devcic et al. described a non-statistically significant trend to longer OS in TARE studies with a lower percentage of pancreatic NET cases, including 70-month OS in a study with $68 \%$ small bowel primary tumors $[16,31]$. The current study evaluated all subtypes of tumors individually and also compared pancreatic primary tumors to other primary sites grouped together. Pancreatic primary NET had the longest median OS (42 months) of any of the primary sites, although it did not reach statistical significance at Kaplan-Meier or Cox Proportional Hazards analysis. There is no randomized prospective data comparing outcomes of TARE or other arterial therapies. At a minimum, the current study suggests that patients with pancreatic NET can be effectively treated with TARE.

Grade 3 constitutional toxicities were uncommon in the current study, with an incidence of $\leq 4 \%$. Two recent single center studies focused on longer term toxicities with TARE for NET $[17,18]$. Given the potentially long survival for low-grade NET, the North American Neuroendocrine Tumor Society expressed concern expressed about chronic toxicity from TARE when used in routine clinical practice [32]. Tomozawa et al. described new ascites 1 year after treatment in 5/29 (17\%) of patients undergoing bilobar therapy [17]. Patients in their study were heavily pretreated with previous resection in $23 \%$ and previous embolization in $26 \%$. Baseline ascites was present in $18 \%$ of patients, a finding present in $6 \%$ of patients in the current study. Tomozawa et al. identified grade 3 hepatic function toxicities in 4 of 52 patients (8\%) 1 year after treatment [17]. By contrast, the current study identified new ascites in $8(5 \%)$ patients without progressive disease at any point of follow-up and longterm grade 3 hyperbilirubinemia in $5(3 \%)$ patients. The current findings more closely mirror those described by $\mathrm{Su}$ et al. [18] While they identified 39 patients out of 54 treated who had new ascites or thrombocytopenia, confounding variables such as hepatic progression were present in 37 patients, leaving 2 (5\%) with toxicity that was clearly attributable to TARE. Currie et al. reviewed incidence of chronic hepatitis following treatment of 91 patients: 63 and 28 underwent chemoembolization and
TARE, respectively. The incidence of grade 3 toxicities attributable to treatment with TARE (14\%) and chemoembolization (3\%) did not reach statistical significance, potentially due to sample size [33].

Only one of the 15 patients (6.7\%) with colonized bile ducts developed a hepatic abscess following TARE. Devulapalli et al. reported a $7.9 \%$ incidence of abscesses in a multi-center review of 126 patients, including 40 with NET, where antibiotic prophylaxis was used in 151 (83.8\%) TARE procedures. Infectious complications were identified in ten patients after 11 procedures. Nine patients in the current group underwent subsequent PRRT with two grade 3 bilirubin toxicities developing in patients with intrahepatic progression at end of life. Enrollment of NET patients in the current study decreased after publication of the NETTER-1 data in 2017 with subsequent FDA approval: 112 NET patients were enrolled from 2015 to 2017 and 58 from 2018 to 2020 [22, 34]. There is limited data of patients who have undergone TARE and PRRT [32].

The current study contains limitations. Sites entered data at self-regulated time points, resulting in less than $100 \%$ entry and evaluation at non-uniform time points. The sample size of this study is relatively small. However, it is the largest multicenter report of TARE in NET patients to date. Dosimetry was largely performed using body-surface area methodology, which has been standard practice until 2021 [35]. Finally, in assessing long-term toxicity, imaging findings such as splenic and liver volumetrics were not available, although other factors such as ascites and hepatic function toxicities were tracked.

\section{Conclusion}

RESiN demonstrates effective therapy for patients with NELM with median OS of 33 months and PFS of 25 months. In a population, toxicity profiles were favorable. Overall, there is no significant OS or PFS difference among different NET primary locations, though we observed the longest OS in NELM patients with pancreatic primary.

\section{Acknowledgements \\ The authors would like to acknowledge the following RESiN investigators: Henry T. Krebs, MD; Mark Sultenfuss, MD; Suvranu Ganguli, MD; Michael Petroziello, MD; Justin Lee, MD; Nicholas Fidelman, MD; Nabeel Akhter, MD; Jafar Golzarian, MD; Michael Soulen, MD; Christopher Grilli, DO, Gary S. Siskin, MD, and Nima Kokabi, MD}

\section{Statement of ethics/study approval}

This study protocol was approved and reviewed by the Vanderbilt Ingram Cancer Center and Vanderbilt University Institutional Review Board (IRB) as GI 1523 (IRB number 150407) and subsequently approved at the other sites.

\section{Authors' contributions}

TYW, KZ, LM, DYS, ASK, DBB contributed to study design. RTG, ZSC, RO, EAW, KV, DYS, DBB acquired data. KZ performed statistical analysis. TYW, DBB, LM, 
DYS and ASK performed data interpretation. TYW and DBB drafted the manuscript. KZ, LM, DYS and ASK provided critical revisions. All authors approved the final manuscript.

\section{Funding}

This study was funded by Sirtex Medical. Acquisition of data, review of data and manuscript preparation was performed by the authors.

\section{Availability of data and materials}

All data generated or analyzed during this study are included in this article. Further enquiries can be directed to the corresponding author.

\section{Declarations}

\section{Ethics approval and consent to participate}

All patients signed informed consent to participate. This study was performed in accordance with the Declaration of Helsinki.

\section{Consent for publication}

Not applicable.

\section{Competing interests}

Ripal T. Gandhi has a research grant from Sirtex Medical, has consulted with Sirtex Medical and Trisalus Life Sciences and has been a speaker for Sirtex Medical.

Zach S. Collins has a research grant from Sirtex Medical, has consulted for Sirtex Medical and has been a speaker for Sirtex Medical.

Eric A. Wang has consulted for Sirtex Medical.

Kirubahara Vaheesan has research grants from Sirtex Medical, Siemens Medical, Merit Medical and Guerbet Medical.

Daniel Y. Sze has a research grant with Sirtex Medical and has consulted for Sirtex Medical.

Andrew S. Kennedy has received institutional grants from Sirtex Medical, Bard Medical and ABK Medical.

Daniel B. Brown has research grants with Sirtex Medical and Guerbet, has consulted with Sirtex Medical, Astra-Zeneca, BTC and Bard Medical, and has been a speaker for Cook Medical.

The other authors have no conflicts to report.

\section{Author details}

${ }^{1}$ Department of Radiology and Radiological Sciences, Vanderbilt University Medical Center, 1161 21st Avenue S, CCC-1118 Medical Center North, Nashville, TN 37232, USA. ${ }^{2}$ Department of Biostatistics, Vanderbilt University Medical Center, Nashville, TN, USA. ${ }^{3}$ Miami Cardiac and Vascular Institute, Baptist Hospital, Miami, FL, USA. ${ }^{4}$ Interventional Radiology, University of Kansas Medical Center, Kansas City, KS, USA. Interventional Radiology, University of Utah Medical Center, Salt Lake City, UT, USA. ${ }^{6}$ Interventional Radiology, Carolinas Medical Center, Charlotte, NC, USA. ${ }^{7}$ Interventional Radiology, Saint Louis University Hospital, St. Louis, MO, USA. ${ }^{8}$ Transplant Surgery, Vanderbilt University Medical Center, Nashville, TN, USA. ${ }^{9}$ Interventional Radiology, Stanford University Medical Center, Palo Alto, CA, USA. ${ }^{10}$ Radiation Oncology, Sarah Cannon Research Institute, Nashville, TN, USA.

Received: 11 November 2021 Accepted: 11 February 2022

Published online: 01 March 2022

\section{References}

1. Dasari A, Shen C, Halperin D, Zhao B, Zhou S, Xu Y, et al. Trends in the incidence, prevalence, and survival outcomes in patients with neuroendocrine tumors in the United States. JAMA Oncol. 2017;3(10):1335-42.

2. Riihimäki M, Hemminki A, Sundquist K, Sundquist J, Hemminki K. The epidemiology of metastases in neuroendocrine tumors. Int J Cancer. 2016;139(12):2679-86.

3. Frilling A, Clift AK. Therapeutic strategies for neuroendocrine liver metastases. Cancer. 2015;121(8):1172-86.

4. Broder MS, Beenhouwer D, Strosberg JR, Neary MP, Cherepanov D. Gastrointestinal neuroendocrine tumors treated with high dose octreotide-LAR: a systematic literature review. World J Gastroenterol. 2015;21(6):1945-55.
5. Rinke A, Wittenberg M, Schade-Brittinger C, Aminossadati B, Ronicke E, Gress TM, et al. Placebo-controlled, double-blind, prospective, randomized study on the effect of Octreotide LAR in the control of tumor growth in patients with metastatic neuroendocrine Midgut tumors (PROMID): results of long-term survival. Neuroendocrinology. 2017;104(1):26-32.

6. Caplin ME, Pavel M, Ćwikła JB, Phan AT, Raderer M, Sedláčková E, et al. Lanreotide in metastatic Enteropancreatic neuroendocrine tumors. N Engl J Med. 2014;371(3):224-33.

7. National Comprehensive Cancer Network. Neuroendocrine and Adrenal Tumors (Version 2.2021) [Internet]. National Comprehensive Cancer Network. 2021 [cited 2021 Jul 22]. Available from: https://www.nccn. org/professionals/physician_gls/pdf/neuroendocrine.pdf

8. Chen JX, Rose S, White SB, El-Haddad G, Fidelman N, Yarmohammadi H, et al. Embolotherapy for neuroendocrine tumor liver metastases: prognostic factors for hepatic progression-free survival and overall survival. Cardiovasc Intervent Radiol. 2017;40(1):69-80.

9. Egger ME, Armstrong E, Martin RCG, Scoggins CR, Philips P, Shah M, et al. Transarterial chemoembolization vs Radioembolization for neuroendocrine liver metastases: a multi-institutional analysis. J Am Coll Surg. 2020;230(4):363-70.

10. Engelman ES, Leon-Ferre R, Naraev BG, Sharma N, Sun S, O'Dorisio TM, et al. Comparison of Transarterial liver-directed therapies for low-grade metastatic neuroendocrine tumors in a single institution. Pancreas. 2014:43(2):219-25.

11. Kennedy A, Bester L, Salem R, Sharma RA, Parks RW, Ruszniewski P, et al. Role of hepatic intra-arterial therapies in metastatic neuroendocrine tumours (NET): guidelines from the NET-liver-metastases consensus conference. HPB. 2015;17(1):29-37.

12. Do Minh D, Chapiro J, Gorodetski B, Huang Q, Liu C, Smolka S, et al. Intra-arterial therapy of neuroendocrine tumour liver metastases: comparing conventional TACE, drug-eluting beads TACE and yttrium-90 radioembolisation as treatment options using a propensity score analysis model. Eur Radiol. 2017;27(12):4995-5005.

13. Fan KY, Wild AT, Halappa VG, Kumar R, Ellsworth S, Ziegler M, et al. Neuroendocrine tumor liver metastases treated with yttrium-90 radioembolization. Contemp Clin Trials. 2016;50:143-9.

14. Tsang ES, Loree JM, Davies JM, Gill S, Liu D, Ho S, et al. Efficacy and prognostic factors for Y-90 Radioembolization (Y-90) in metastatic neuroendocrine tumors with liver metastases. Can J Gastroenterol Hepatol. 2020;2020:e5104082.

15. Helmberger T, Golfieri R, Pech M, Pfammatter T, Arnold D, Cianni R, et al. Clinical application of trans-arterial Radioembolization in hepatic malignancies in Europe: first results from the prospective multicentre observational study CIRSE registry for SIR-spheres therapy (CIRT). Cardiovasc Intervent Radiol. 2021;44(1):21-35.

16. Devcic Z, Rosenberg J, Braat AJA, Techasith T, Banerjee A, Sze DY, et al. The efficacy of hepatic $90 Y$ resin Radioembolization for metastatic neuroendocrine tumors: a meta-analysis. J Nucl Med. 2014;55(9):1404-10.

17. Tomozawa Y, Jahangiri Y, Pathak P, Kolbeck KJ, Schenning RC, Kaufman JA, et al. Long-term toxicity after Transarterial Radioembolization with Yttrium-90 using resin microspheres for neuroendocrine tumor liver metastases. J Vasc Interv Radiol. 2018;29(6):858-65.

18. Su Y-K, Mackey RV, Riaz A, Gates VL, Benson AB, Miller FH, et al. Longterm hepatotoxicity of Yttrium-90 Radioembolization as treatment of metastatic neuroendocrine tumor to the liver. J Vasc Interv Radiol. 2017:28(11):1520-6.

19. Currie BM, Hoteit MA, Ben-Josef E, Nadolski GJ, Soulen MC. Radioembolization-induced chronic hepatotoxicity: a single-center cohort analysis. J Vasc Interv Radiol. 2019;30(12):1915-23.

20. Braat AJAT, Ahmadzadehfar H, Kappadath SC, Stothers CL, Frilling A, Deroose CM, et al. Radioembolization with $90 \mathrm{Y}$ resin microspheres of neuroendocrine liver metastases after initial peptide receptor radionuclide therapy. Cardiovasc Intervent Radiol. 2020;43(2):246-53.

21. Memon K, Lewandowski RJ, Mulcahy MF, Riaz A, Ryu RK, Sato KT, et al. Radioembolization for neuroendocrine liver metastases: safety, imaging, and long-term outcomes. Int J Radiat Oncol Biol Phys. 2012;83(3):887-94.

22. Strosberg J, El-Haddad G, Wolin E, Hendifar A, Yao J, Chasen B, et al. Phase 3 trial of 177 Lu-Dotatate for Midgut neuroendocrine tumors. N Engl J Med. 2017;376(2):125-35. 
23. Lawrence B, Gustafsson BI, Chan A, Svejda B, Kidd M, Modlin IM. The epidemiology of gastroenteropancreatic neuroendocrine tumors Endocrinol Metab Clin N Am. 2011;40(1):1-18 vii.

24. Gupta S, Johnson MM, Murthy R, Ahrar K, Wallace MJ, Madoff DC, et al. Hepatic arterial embolization and chemoembolization for the treatment of patients with metastatic neuroendocrine tumors. Cancer. 2005;104(8):1590-602.

25. Eriksson BK, Larsson EG, Skogseid BM, Löfberg AM, Lörelius LE, Öberg KE. Liver embolizations of patients with malignant neuroendocrine gastrointestinal tumors. Cancer. 1998;83(11):2293-301.

26. Moertel CG, Johnson CM, McKusick MA, Martin JK, Nagorney DM, Kvols LK, et al. The Management of Patients with advanced carcinoid tumors and islet cell carcinomas. Ann Intern Med. 1994;120(4):302-9.

27. Nave H, Mössinger E, Feist H, Lang H, Raab H-R. Surgery as primary treatment in patients with liver metastases from carcinoid tumors: a retrospective, unicentric study over 13 years. Surgery. 2001;129(2):170-5.

28. Pape U-F, Böhmig M, Berndt U, Tiling N, Wiedenmann B, Plöckinger U. Survival and clinical outcome of patients with neuroendocrine tumors of the Gastroenteropancreatic tract in a German referral center. Ann N Y Acad Sci. 2004;1014(1):222-33.

29. Ezziddin S, Meyer C, Kahancova S, Haslerud T, Willinek W, Wilhelm K, et al. 90Y Radioembolization after radiation exposure from peptide receptor radionuclide therapy. J Nucl Med. 2012;53(11):1663-9.

30. Saxena A, Chua TC, Bester L, Kokandi A, Morris DL. Factors predicting response and survival after Yttrium-90 Radioembolization of Unresectable neuroendocrine tumor liver metastases: a critical appraisal of 48 cases. Ann Surg. 2010;251(5):910-6.

31. Kennedy AS, Dezarn WA, McNeillie P, Coldwell D, Nutting C, Carter D, et al. Radioembolization for Unresectable neuroendocrine hepatic metastases using resin 90Y-microspheres: early results in 148 patients. Am J Clin Oncol. 2008:31(3):271-9.

32. Strosberg JR, Halfdanarson TR, Bellizzi AM, Chan JA, Dillon J, Heaney AP, et al. The north American neuroendocrine society (NANETS) consensus guidelines for surveillance and medical Management of Midgut Neuroendocrine Tumors. Pancreas. 2017;46(6):707-14.

33. Currie BM, Nadolski G, Mondschein J, Dagli M, Sudheendra D, Stavropoulos SW, et al. Chronic hepatotoxicity in patients with metastatic neuroendocrine tumor: Transarterial chemoembolization versus Transarterial Radioembolization. J Vasc Interv Radiol. 2020;31(10):1627-35.

34. United States Food and Drug Administration. FDA approves new treatment for certain digestive tract cancers [internet]. FDA FDA; 2018 [cited 2021 Sep 8]. Available from: https://www.fda.gov/news-events/pressannouncements/fda-approves-new-treatment-certain-digestive-tractcancers

35. Levillain H, Bagni O, Deroose CM, Dieudonné A, Gnesin S, Grosser OS, et al. International recommendations for personalised selective internal radiation therapy of primary and metastatic liver diseases with yttrium-90 resin microspheres. Eur J Nucl Med Mol Imaging. 2021;48(5):1570-84.

\section{Publisher's Note}

Springer Nature remains neutral with regard to jurisdictional claims in published maps and institutional affiliations.

Ready to submit your research? Choose BMC and benefit from:

- fast, convenient online submission

- thorough peer review by experienced researchers in your field

- rapid publication on acceptance

- support for research data, including large and complex data types

- gold Open Access which fosters wider collaboration and increased citations

- maximum visibility for your research: over $100 \mathrm{M}$ website views per year

At BMC, research is always in progress.

Learn more biomedcentral.com/submissions 